\title{
Prática docente assistencial: compartilhamento de açóes para o ensino na atenção primária em saúde
} Practices in clinical teaching: sharing actions for teaching in primary health care Práctica asistencial docente: compartir acciones para la enseñanza en la atención primaria de la salud

Katheri Maris Zamprogna ${ }^{1}$

(iD) https://orcid.org/0000-0002-5987-1025

Vânia Marli Schubert Backes

(iD https://orcid.org/0000-0002-6217-4212

Jouhanna do Carmo Menegaz ${ }^{2}$

(iD https://orcid.org/0000-0002-7655-9826

Gilberto Tadeu Reis Silva ${ }^{3}$

(iD https://orcid.org/0000-0002-0595-0780

Maria Luiza Carvalho de Oliveira ${ }^{4}$

(iD) https://orcid.org/0000-0002-1077-1066

Fernanda Moreira Ribeiro Fraga ${ }^{3}$

(iD) https://orcid.org/0000-0002-0502-3442

Francisco Reis Tristão ${ }^{1}$

(iD https://orcid.org/0000-0003-1451-4566

${ }^{1}$ Universidade Federal de Santa Catarina, Florianópolis, Santa Catarina, Brasil

${ }^{2}$ Universidade do Oeste de Santa Catarina, Chapecó, Santa Catarina, Brasil

${ }^{3}$ Universidade Federal da Bahia, Salvador, Bahia, Brasil

${ }^{4}$ Universidade do Estado do Amazonas, Amazonas, Manaus, Brasil

Autor de correspondência Katheri Maris Zamprogna E-mail: katherizamprogna@gmail.com

\section{Resumo}

Enquadramento: A prática docente na atenção primária é complexa, podendo a comunidade de prática servir como espaço de formaçáo pedagógica para os enfermeiros supervisores e enfermeiros docentes. Objetivo: Descrever as açóes identificadas por enfermeiros supervisores e enfermeiros docentes em comunidade de prática docente assistencial no ensino na atenção primária em saúde.

Metodologia: Pesquisa-ação, qualitativa, realizada com grupos focais com 13 enfermeiros supervisores da atenção primária e enfermeiros docentes. Utilizou-se o software de análise de dados AtlasTi 8, e análise de conteúdo de Bardin.

Resultados: Obtiveram-se três categorias: Açóes dos enfermeiros docentes para a qualificação da formação em enfermagem na atençáo primária em saúde; Açóes dos enfermeiros supervisores para a qualificação da formação em enfermagem na atenção primária em saúde; Açóes das Instituiçōes de Ensino e de Saúde para a qualificação da prática docente na atenção primária em saúde.

Conclusáo: Os membros constituíram-se enquanto uma comunidade de prática, pois compartilharam interesses comuns, levando ao engajamento sobre definição de açóes no exercício docente com especificidade na atenção primária.

Palavras-chave: ensino superior; educação em enfermagem; atenção primária à saúde; comunidade de prática

\section{Abstract}

Background: Teaching in primary health care is complex, and the community of practice (COP) can be a place of pedagogical training for nurse tutors and nurse teachers.

Objective: To describe the actions identified by nurse tutors and nurse teachers of a COP in primary care teaching.

Methodology: Qualitative participatory action research carried out with 13 primary care nurse tutors and nurse teachers using focus groups. Data analysis used the Atlas Ti 8 software program, following Bardin's content analysis approach.

Results: Three categories emerged: Nurse teachers' actions for the qualification of nursing education in Primary Health Care; Nurse tutors' actions for the qualification of nursing education in Primary Health Care; and Education and Health Institutions' actions for the qualification of teaching practices in Primary Health Care.

Conclusion: The participants established a COP because they shared common interests, which led to the commitment to defining actions in primary health care teaching.

Keywords: education, higher; education, nursing; primary health care; community of practice

Resumen

Marco contextual: La práctica docente en atención primaria es compleja, y la comunidad de práctica puede servir como espacio de formación pedagógica para los enfermeros supervisores y enfermeros docentes.

Objetivo: Describir las acciones identificadas por los enfermeros supervisores y enfermeros docentes en la comunidad de práctica docente asistencial en la enseñanza de la atención primaria de la salud. Metodología: Investigación-acción cualitativa realizada mediante grupos focales con 13 enfermeros supervisores de atención primaria y enfermeros docentes. Se utilizó el software de análisis de datos AtlasTi 8 y el análisis de contenido de Bardin.

Resultados: Se obtuvieron tres categorías, Acciones de los enfermeros docentes para la cualificación de la enseñanza de la enfermería en la atención primaria de la salud; Acciones de los enfermeros supervisores para la cualificación de la formación en enfermería en la atención primaria de la salud; Acciones de las instituciones de Enseñanza y salud para la cualificación de la práctica docente en la atención primaria de la salud.

Conclusión: Los miembros se constituyeron como una comunidad de práctica, ya que compartían intereses comunes, lo que los llevó a comprometerse en la definición de acciones en el ejercicio docente, con especificidad en la atención primaria.

Palabras clave: educación superior; educación en enfermería; atención primaria de salud; comunidade de práctica

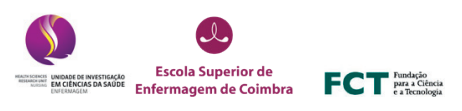

Como citar este artigo: Zamprogna, K. M., Backes, V. M., Menegaz, J. C., Silva, G. T., Oliveira, M. L., Fraga, F. M., \& Tristão, F. R. (2021). Prática docente assistencial: compartilhamento de açóes para o ensino na atençāo primária em saúde. Revista de Enfermagem Referência, 5(5), e20080. https://doi.org/10.12707/RV20080 


\section{Introdução}

A integração ensino-serviço é um elemento que impulsiona mudanças na formação dos profissionais de saúde. Como dinâmica que aproxima a formação dos profissionais de saúde ao contexto real de vida das pessoas e comunidade, o ensino para o trabalho no Sistema Único de Saúde (SUS) é um elemento fundamental, dado que a regulamentação do mesmo explicita o dever do campo de atuação do SUS na ordenaçáo da formaçáo na área da saúde (Ministério da Saúde, Secretaria de Gestão do Trabalho e da Educação na Saúde, Departamento de Gestão da Educação na Saúde, 2004).

Nesta perspectiva, programas e políticas foram impulsionados, como a Política Nacional de Educação Permanente (Ministério da Saúde, 2004), entre outras.

Entretanto, a proporcionalidade de movimentos criados no sentido de integrar o ensino em serviço à comunidade não acompanhou o estabelecimento de acordos entre as instituiçôes de ensino e os serviços de saúde, relativamente ao desenvolvimento organizado dessa estratégia de educação (Silva et al., 2018).

O que se percebe, é a dicotomia de objetivos entre ambas as instituiçóes, dando espaço a movimentos unilaterais, sem a participação dos serviços de saúde nas instituiçôes de ensino, caracterizando de forma pontual as experiências de integração entre os gestores, desarticulando a incorporação do currículo na rotina dos serviços de saúde (Zarpelon et al., 2018).

Com isto, é possível que outras problemáticas venham a surgir, como referem Pinto e Cyrino (2015), ao apontarem o desempenho de atividades de ensino em serviço, por vezes, em estruturas deficitárias, que não foram preparadas para comportarem os estudantes e as necessidades pedagógicas, ficando o processo de aprendizagem aquém de açóes importantes, especialmente da formação para a atenção primária em saúde (APS), foco deste estudo, como a realização de grupos e atividades educativas direcionadas para a prevenção de doenças e promoção de saúde.

É também importante mencionar as questôes associadas ao comprometimento entre os corresponsáveis do desenvolvimento de atividades de ensino junto dos serviços de saúde, evidenciando a sua operacionalização no sistema, como atividade secundarizada, deslegitimando o papel formador do SUS (Pinto \& Cyrino, 2015).

Neste processo, a celebração dos contratos organizativos de ação pública ensino-saúde (COAPES), foi uma estratégia importante de regulamentação da relação entre as instituições para o processo de mudança (Silva et al., 2018). Isso evidencia, de certa forma, a existência de um olhar sobre as fragilidades das políticas e diretrizes acerca da formação em serviço, muito embora os desafios ainda permaneçam, fazendo-se necessária a indução de açôes que qualifiquem ainda mais esta atividade.

Neste sentido, este estudo teve como objetivo descrever as ações identificadas por enfermeiros supervisores e enfermeiros docentes em comunidade de prática docente assistencial no ensino na APS.

\section{Enquadramento}

Os professores têm um papel fundamental no avanço de inovações e transformação efetiva na educação de nível superior (Silva et al., 2018). Mas, para que isso ocorra, há a necessidade de açóes que promovam a formação docente, diante dos desafios da reorientação da formação de profissionais de saúde que fortaleçam a tríade ensino-serviço-comunidade.

A comunidade de prática definida por Wenger (2011) como grupo de membros que compartilham responsabilidades ou paixão por uma temática, potencializa a articulação entre os atores do ensino na APS. Assim, o autor (2011) reconhece na constituição de comunidades de prática, um caminho à aprendizagem e à mudança, por ser contexto de negociação de significados e estabelecimento de compromissos.

Wenger (2011) também define que a comunidade de prática constitui-se por engajamento de indivíduos com enfoque num interesse comum. O seu desenvolvimento ocorre pela definiçáo de significados a partir da interação dos membros que constituem a comunidade de prática, com enfoque primordial na prática, considerando a dimensão do fazer num contexto social, agregado a questôes históricas, políticas, económicas, bem como, na construção de identificaçôes das formas de ser neste contexto. Trata-se de um conceito de interaçáo de grupos de pessoas que se debruçam sobre um determinado conhecimento.

Para compreender o que está implícito no quotidiano do trabalho do profissional, como crenças, valores, atitudes e conhecimentos, é necessário um processo de reflexão, o qual ressignifica a ação e promove a redefinição de significados.

Nesse sentido, Wenger (2011) considera que a associação entre prática e comunidade não significa dizer que qualquer coisa constituiria uma comunidade de prática, dado que para associar ambos os termos são necessárias algumas dimensóes que dão coerência a uma comunidade. Assim, Wenger (2011) destaca três dimensóes no que tange uma comunidade de prática, sendo elas o engajamento mútuo, que são as competências de cada participante, o que fazem para alcançar o que ainda não sabem; empreendimento conjunto, que se trata de um objetivo em comum, oriundo do compromisso mútuo entre os membros, e repertório compartilhado, que são maneiras de comportamento que o grupo adquiriu ao longo do processo de integração, como jeito de falar, documentos que construíram, olhares.

\section{Questáo de Investigaçáo}

Quais as ações identificadas por enfermeiros supervisores e enfermeiros docentes em comunidade de prática docente assistencial para o ensino na APS?

\section{Metodologia}

Estudo de carácter qualitativo do tipo pesquisa-açáo, desenvolvido através de cinco grupos focais que tiveram 
duração média de 2 a 3 horas cada, tendo sido aprovado pelo Comité de Ética em Pesquisa sob CAAE no 83737518.0.0000.0121.

Foi desenvolvido num município da região sul do Brasil, no estado de Santa Catarina, a partir da parceria com uma instituiçáo de ensino superior (IES) e com os campos de prática da APS de um órgão público. Assim, os locais de desenvolvimento deste estudo foram nas unidades básicas de saúde (UBS) vinculadas à secretaria municipal de saúde, em articulação com a IES.

Para a execução do estudo, seis UBS foram previamente selecionadas. Consideraram-se como unidades de grande porte as que fossem constituídas por mais do que uma equipa de Estratégia de Saúde da Família. Os participantes deste estudo foram os enfermeiros docentes de enfermagem, que realizavam atividades de ensino prático na APS, vinculados a uma IES de carácter privado que desempenha as suas atividades teórico-práticas nas UBS do município. Ainda, foram incluídos os enfermeiros vinculados à instituição municipal de saúde, à secretaria municipal de saúde que acompanham os discentes em enfermagem, que estão a realizar atividades práticas de ensino na APS, nessas UBS. Convencionou-se para este trabalho denominar o primeiro grupo de participantes como enfermeiros docentes e o segundo, dos profissionais vinculados à instituição de saúde, como enfermeiros supervisores.

Foram considerados critérios de inclusão dos docentes da IES, profissionais graduados em enfermagem, que exercem funções de docência no ensino superior em saúde como professores de discentes de enfermagem, em atividades teórico-práticas, na APS, possuindo vínculo empregatício na IES selecionada e atuação na formação discente em APS há pelo menos seis meses. Os critérios de exclusão foram: docentes em enfermagem que estivessem de licença, férias ou afastados do trabalho no momento da colheita de dados.

No total, participaram no estudo sete docentes vinculados à IES de carácter privado, para além de seis enfermeiros da Estratégia de Saúde da Família, que exerciam funçôes nas UBS selecionadas no desenvolvimento do estudo, totalizando treze participantes. Os dados foram recolhidos no período de junho a outubro de 2018.

Realizou-se contacto individual através de correio eletrónico para realizar o convite para a participação no estudo, determinando posteriormente o dia, local e horário para o primeiro momento. Os cinco momentos, ou seja, cinco grupos focais foram realizados através de perguntas norteadoras à luz de Wenger (2011), sobre as dimensões da comunidade de prática, para alcance das açóes propostas. Os grupos foram conduzidos por meio das perguntas: Como me constituí professor de enfermagem e enfermeiro supervisor na UBS? Quais os problemas/necessidades que considero essenciais para serem refletidas que toca à formação inicial e permanente como docente e como assistencial que supervisiona estudantes de enfermagem? $\mathrm{O}$ que conheço sobre formação docente-assistencial? Como se fundamenta a minha prática docente-assistencial na UBS? Que açóes proponho para modificar a minha prática atual com base nos referenciais teóricos estudados? Quais os compromissos que assumo (individualmente) diante do trabalho desenvolvido coletivamente?

Os dados qualitativos foram obtidos por meio de gravação, sendo transcritos e analisados a partir da análise de conteúdo de Bardin (2011), utilizando-se o software de análise de dados AtlasTi8, para a codificação escrita e categorização dos textos referentes aos cinco momentos da pesquisa. Utilizaram-se, neste texto, oito codificaçóes, contendo 23 excertos significativos, agrupados em três categorias que revelaram as açóes a serem realizadas por cada interveniente desse cenário de ensino. De forma a preservar o anonimato dos participantes, os constructos dos resultados deste manuscrito utilizam a letra $\mathrm{D}$ para os enfermeiros docentes e E, para os enfermeiros supervisores. Tais letras, sequenciadas por número, dizem respeito à ordenação da codificação no AtlasTi 8 de cada excerto significativo (quotation).

\section{Resultados}

Os resultados evidenciaram três categorias que expuseram as açóes dos membros da comunidade, sendo elas: Açóes dos enfermeiros docentes para a qualificação da formação em enfermagem na APS; Açóes dos enfermeiros supervisores para a qualificação da formação em enfermagem na APS; Açóes das Instituiçóes de Ensino e de Saúde para a qualificação da prática docente na atenção primária em saúde.

Quanto aos enfermeiros docentes, como ações para a qualificação da formação em enfermagem na APS, eles referem a necessidade de definir papéis sobre a atuação como docente de enfermagem no momento do processo de ensino

Lá em Areias, eu fui professora há muitos anos, e a coordenadora dizia que eu era a quarta enfermeira da unidade, havia paciente que ligava e queria falar comigo em horário que eu não estava. Eu sempre dizia: "Estou aqui como IES". A gente tem que estar o tempo todo mediando e nos colocando em nossos lugares ... Eu já tive momentos em que eu estava como a única enfermeira... uma tinha ido a uma reunião e "a outra falou que tu estarias aqui”. Não! Espera aî́?!. (D01)

"Eu vejo a importância de preparar o campo, porque a gente respeita o atendimento por área que tem os enfermeiros que são os responsáveis. Eu sou uma enfermeira também, mas eu estou como IES" (D03).

Sem deixarem de mencionar a articulação das açôes e conteúdos a serem enfocadas no âmbito do ensino na APS, entre enfermeiro docente e enfermeiro supervisor daquela unidade de saúde:

Acho bastante importante essa articulação com os enfermeiros da Unidade, para organizar as açóes que a gente vai realizar no campo de estágio ... Eu fico dois meses com o mesmo grupo de alunos, dá pra ver a Atenção Básica em toda sua complexidade e na sua amplitude. Portanto, essa articulação do enfermeiro do que podemos realizar é muito importante para o professor e para o aluno. (D04) 
Teve unidade que eu estudei tanto, eu e a enfermeira juntas e o aluno também. Então a gente acaba forçosamente tendo que aprender. Isso exige que tu tenhas muito mais preparo do que lá no hospital, porque lá é a minha "praia" e dificilmente vai dar algum problema ... Na Atenção Básica, é todo dia uma coisa diferente, uma situação diferente. Então o preparo do professor é fundamental. (D02) Nessa dimensão, reconhecem também que não somente o enfermeiro supervisor, mas também a equipa colabora no ensino e tem um importante papel nele: "O professor está ali pra orientar, ensinar, pra acompanhar, pra mediar, mas também o enfermeiro da Unidade e outros que trabalham ali, acabam contribuindo também para o aprendizado do aluno" (D02).

No núcleo da definição das açōes necessárias para o ensino na APS, a comunidade de prática permitiu revelar escolhas didáticas dos docentes de enfermagem, tendo em conta a etapa curricular de cada discente:

$\mathrm{Eu}$ assumo todas as agendas dos enfermeiros, portanto, aonde eu estou, como eu sou da $9^{a}$ fase que, teoricamente, é um aluno que já está se formando e que deveria ter o seu conhecimento mais aprofundado, são as consultas, são os atendimentos, eu assumo tudo e faço com que o aluno experimente exatamente isso. Então: "agora você tem que terminar o atendimento e fazer tudo" porque, é o que o enfermeiro tem que fazer. (D03)

Quanto aos enfermeiros supervisores, para a qualificação da formação em enfermagem na APS, eles reconhecem que a atuação da equipa tem impacto na formação do profissional enfermeiro, numa dimensão que expõem a necessidade de serem exemplos para os discentes em enfermagem:

Eu sempre falo para minha equipe: que profissionais vocês iriam querer encontrar se vocês fossem os estagiários? Então, procurem ser para eles o que vocês gostariam de encontrar aqui se vocês fossem estagiários. Quando a gente é estagiário, a gente tem expectativas, chega lá e é tudo completamente diferente, frustra! (E06)

Neste sentido, os enfermeiros supervisores reconhecem a importância que tem o estímulo aos discentes para participarem nas atividades junto deles, mencionando a importância dos envolvimentos dos professores também: articular com o enfermeiro da UBS as participaçôes de Saúde em suas atividades, tentar envolver. O tempo, sabemos que é corrido, mas é bom motivar ... ir puxando o aluno para participar de todas as atividades e também das consultas ... que o professor se disponibilize a fazer esse atendimento também, agendas, preventivos, pré-natal. Para que ele também possa visualizar como é o trabalho do enfermeiro. (E02)

Finalmente, tanto os enfermeiros docentes como os enfermeiros supervisores referem a necessidade de antecipar o contacto da IES com a UBS na qual irão desenvolver o ensino:

A gente, enquanto profissional de campo de estágio, precisa participar antes de começar as atividades com uma reuniáo de Unidade, promover essa empatia com todos os profissionais. Acho que seria um momento importante, porque quando a gente entra com os alunos, tem que olhar os alunos . . . às vezes a gente não consegue dizer o que é o nosso trabalho; o que é que a gente espera deles e o que é que eles podem esperar da gente enquanto no campo de estágio. (D03)

O espaço físico para receber o aluno é importante, precisa estruturar a equipe, ver se tem algum local para o aluno e ver com a Instituição de Ensino quais são os dias e tentar encaixar, rever as agendas pra liberar uma sala, ver horários pra atender aos alunos; a responsável por isso é a equipe da UBS. (E01)

Ainda, referem a importância do serviço de saúde ser reconhecido como local de ensino, sendo importante essa sensibilização junto da equipa e também, com a gerência da instituição de saúde. Os excertos seguintes demonstram a compreensão de que a inserção do grupo nas unidades vai além do processo de ensino-aprendizagem do aluno, pois contribuiria para o trabalho qualitativo da mesma: a questão da dinâmica da unidade que acaba atrapalhando... Mas eu acho que o nosso trabalho é de ter uma parceria, eu acho que a gente trabalha junto com a equipe da Unidade. Então, esse é o nosso grande objetivo, de inserir os alunos ali, dentro das Unidades para que eles possam contribuir com o trabalho da unidade. (D02)

A necessidade de sensibilizar o aluno em relaçáo ao conhecimento teórico acerca de políticas sobre o SUS. Então, a gente pensou em proporcionar momentos de discussão e troca sobre a Atenção Básica, não apenas para os alunos, mas para toda aquela equipe de profissionais de Atenção Básica, pessoas da assistência e da gerência da Atenção Básica, por exemplo, para gerar essa discussão. (D04)

\section{Discussão}

A realização do processo de ensino-aprendizagem nos serviços de saúde é uma prática que tem gerado discussão. Diante disso, surge a preocupação sobre formas e maneiras de aprimorá-la, particularmente na APS, serviço com inúmeras especificidades e que responde a uma parte importante dos problemas de saúde pública (Ministério da Saúde, 2017).

Tal, justifica-se pelas características da APS que aproximam a equipa de saúde do utente, permitindo que se conheça a pessoa, família e comunidade, garantindo adesão aos tratamentos e intervençóes, levando à maior resolutividade dos problemas de saúde (Ministério da Saúde, 2017), que certamente diminuem as intervençóes em níveis de atenção que geram custos mais elevados, como a média e alta complexidade.

Ao passo que tais açóes têm vindo a ser fortificadas, surge a necessidade de garantia de formaçáo de profissionais qualificados, corroborando Sales et al. (2015), que também destacam que no contexto tecnológico e científico avançado, sendo a assistência em saúde uma atividade 
de trabalho humano, a formação de profissionais torna-se condição sine qua non. Desta forma, os espaços de encontro para problematizar a integração entre a academia e serviço de saúde são ferramentas primordiais à efetivação das relações entre os atores desse cenário. Assim, a comunidade de prática (Wenger, 2011), por se focar no compartilhamento de boas práticas, criando novos conhecimentos para melhorar uma atividade profissional, corrobora a formação contínua de profissionais que quotidianamente vivenciam esse ensino e que, por isso, reconhecem as nuances a serem trabalhadas para a sua melhoria. Nesta perspectiva de avanço, justifica-se o movimento de realização de comunidade de prática docente-assistencial que inclua os intervenientes envolvidos, a fim de operacionalizar açôes correspondentes à especificidade da APS.

A sua importância encontra-se especialmente nas três dimensóes necessárias à sua efetivaçáo (engajamento mútuo; empreendimento conjunto e repertório compartilhado), em que o engajamento mútuo se estabelece pelas competências de cada participante ou seja, o que realizam, as suas habilidades, o que fazem para alcançar o que ainda não sabem. Além disso, esta dimensáo transpóe uma comunidade abstrata a algo mais concreto, porque a prática passa a existir visto que as pessoas participam em ações cujo significado negoceiam mutuamente, deste feito, a prática reside numa comunidade de pessoas e nas relaçóes mútuas que constroem. Esta afiliação à comunidade torna-se o compromisso mútuo, e embora pareça que para que isso ocorra, far-se-ia necessário convívio próximo, não é isso que lhe determina uma prática, mas sim a manutenção de relaçóes densas, organizadas em torno do tema que lhes interessa, conforme apresentado nos resultados do estudo que incluiu enfermeiros e docentes envolvidos sobre uma mesma ótica (Wenger, 2011). E, se considerarmos que no aspecto da formação em saúde, especialmente da APS, uma série de necessidades são exigidas, seja da ordem dos utentes, das demandas do serviço, do sistema de saúde ou dos componentes curriculares, aproximar os docentes da IES aos enfermeiros supervisores à luz das particularidades do envolvimento mútuo, torna-se uma ação estratégica para decisōes conjuntas face aos problemas (Hita et al., 2018). Assim, da forma que esta comunidade se apresenta, o seu desenvolvimento tem grande potencial de elevar uma experiência de discussão a uma atitude protagonista, no sentido de os membros colaborarem entre si e ampliarem o olhar crítico sobre as demandas do exercício docente. Deste compartilhamento pela comunidade, resoluçóes mais efetivas, mais elaboradas são construídas, sendo este, provavelmente, um dos principais avanços desta experiência.

Â medida que os indivíduos elaboram projetos e neles se envolvem coletivamente, eles acabam por se adaptarem aos colegas. Juntas, as pessoas aprendem a colaborar, produzindo novas formas de trabalho e novos conhecimentos. Estas práticas, se consolidadas com uma populaçáo que possua adesão ao tema de discussão da comunidade, seja ele qual for, tem grande potencial de construção de um empreendimento coletivo. Desta perspectiva, Wenger (2011) concluiu que o termo comunidade de prática é o mais apropriado para descrever a relação estabelecida neste coletivo de indivíduos. Assim, Wenger (2011) definiu o termo de objetivo comum, empreendimento conjunto, como dimensão que auxilia a compreensão do contexto, pois é uma construção conjunta entre os indivíduos interessados, sobre um determinado tema, determinado conhecimento. É possível negociar compromissos, a partir da escolha do que será ou não ignorado, do que será ou não será feito. $\mathrm{E}$ tal dimensão não deve ser tratada como uma simples meta, dado que surge em virtude de um processo coletivo de negociação, oriundo do compromisso mútuo entre os membros.

Neste sentido, mediante a estruturação de açôes que fossem mais efetivas e reais ao cenário de discussão, os participantes evidenciaram a necessidade de definição de papéis, no que toca à função do docente de enfermagem, proveniente da IES. Num estudo realizado sobre as dificuldades na integração entre a academia e serviço de saúde, percebeu-se que um dos motivos que leva a uma confusão de papéis ocorre pela sobrecarga de trabalho do enfermeiro da equipa, delegando funções aos enfermeiros docentes que, a priori, são da responsabilidade do enfermeiro da unidade, incompatíveis com o objetivo central de atuaçáo do enfermeiro docente (Sales et al., 2015).

De certa forma, esta situaçáo fragiliza o planeamento do docente de enfermagem, devido à sua utilização como mão de obra, oriunda da insuficiência de funcionários que deem conta das necessidades das unidades de saúde, sugerindo, portanto, a necessidade de esclarecimento acerca da especificidade da função do enfermeiro docente em local assistencial.

Por outro lado, os enfermeiros docentes consideram que em razão de terem a mesma formação, na área de enfermagem, com os enfermeiros supervisores, o convívio diário leva à troca positiva de conhecimentos, considerado via de mão dupla, em que ora auxilia no desenvolvimento do serviço, ora no ensino discente.

Como ação prévia à inicialização do ensino em serviço, os enfermeiros docentes sugerem a preparação e troca de informaçóes com os enfermeiros supervisores, não apenas para firmar processos organizativos, mas numa perspectiva de se preparar para o conteúdo, possivelmente pela complexidade de atuação do enfermeiro da Estratégia de Saúde da Família, o qual tem atribuição específica de assistência integral aos indivíduos e famílias em todas as fases de desenvolvimento humano, desde a infância à terceira idade; realizando consultas de enfermagem; supervisão do trabalho dos agentes comunitários de saúde e equipa; com atribuiçóes de gestão das unidades de saúde (Ministério da Saúde, 2017).

E, é neste processo que a terceira dimensão da comunidade de prática toma forma, considerando-se o repertório compartilhado, uma vez que neste estão integradas formas de comportamento que o grupo adquiriu ao longo do processo de integração, construído de forma verbalizada, por meio de olhares, de gestos, de símbolos, de características incorporadas. Para Wenger (2011), ao passo que os membros interagem e reflexionam mediante um tema que os aproxima, esta atuação conjunta cria recursos para negociar significados, e desta forma, o repertório de uma 
comunidade pode incluir rotinas, palavras, instrumentos, conceitos adotados ou produzidos no seu decurso, conteúdos, e que, desta forma, passam a fazer parte da prática dos membros.

Para Shulman (2005), o conhecimento de conteúdo é essencial ao ser professor. Trata-se de conhecimento referente à bibliografia e estudos acumulados, abordando ideias e habilidades que são importantes numa área em específico, exigindo-se do professor, aprofundar os seus conhecimentos na dimensão do que ensina. Shing et al. (2015), descrevem que o conhecimento de conteúdo de Lee Shulman é sobre o que se está a ensinar, associado ao conhecimento pedagógico de conteúdo do autor, tratar-se-ia de como ensiná-lo. Backes et al. (2017) dão ênfase a esse conhecimento, enfatizando que dominá-lo é ampliar possibilidades de intervençóes docentes.

Possivelmente, em virtude da atuação na APS ser uma atividade multiprofissional (Ministério da Saúde, 2017), os docentes reconhecem que a relação com outros profissionais das equipas também tem impacto na aprendizagem discente. Esta situaçáo sugere a necessidade de fomento curricular na formação inicial, a outras profissóes da área da saúde, para além da enfermagem, que inclua aspectos didático-pedagógicos e movimentos de sensibilização sobre a função de formaçáo dos recursos humanos nos serviços do SUS.

Sendo assim, a aprendizagem para a APS dar-se-ia numa dimensão que vai desde o aspecto micro, singular do exercício de enfermagem, ao aspecto macro, envolvendo outros componentes do trabalho em equipa interdisciplinar. Para Rostelatto e Dallacosta (2018), os discentes, ao realizarem estágio curricular supervisionado, sentem necessidade de serem cuidados e, nesse sentido, é necessária a troca entre a equipa, a fim de que o aluno se sinta parte integrante do grupo para exercer as suas atividades com mais desenvoltura. Nesse mesmo estudo, evidenciou-se que mesmo situaçóes consideradas positivas ou negativas, vivenciadas pelos discentes junto à equipa, contribuem para a aprendizagem, uma vez que refletem as dificuldades enfrentadas no quotidiano de trabalho. Portanto, é possível compreender as experiências práticas no mundo do trabalho, principalmente no ensino em enfermagem, como potenciais influenciadoras do futuro da profissão e na consolidação da esfera da APS (Brehmer $\&$ Ramos, 2017).

Os enfermeiros supervisores também compartilham com essa leitura dos docentes de enfermagem, pois relatam que a maneira como se comporta a equipa é exemplo para a formação do futuro profissional.

Para dar conta do processo de ensino-aprendizagem no que diz respeito à APS, os docentes revelam atitudes, como assumir todas as atividades programadas ao enfermeiro da equipa, sem esquecer do momento formativo em que o discente promove sinergia entre as atividades educacionais elegidas, aos objetivos curriculares. Tal formalização presente no currículo é necessária e, de facto, proporciona ao docente esquemas de significados e regras de atuação que o levem à prática docente com algumas garantias mínimas (Moya et al., 2018). No entanto, por mais que as expressóes encontradas nos achados do es- tudo levem à compreensão de que por estar em etapa avançada curricularmente, os discentes estariam aptos a exercerem todos os tipos de atividades que concernem ao enfermeiro, é preciso atentar-se ao equívoco de redução de outras questôes constituintes desse processo, dado que a missão de ensino exige uma integração do conhecimento pedagógico do conteúdo, com aspetos para além do currículo e que envolva também o conhecimento dos alunos e outras esferas (Herold, 2019).

Quando se trata dos enfermeiros supervisores, percebe-se entre os participantes a consciência sobre a influência que as suas açóes e escolhas exercem no desenvolvimento do ensino no âmbito do serviço.

Um estudo realizado na Universidade de Lisboa com 168 estudantes de enfermagem, o qual analisou o efeito da função do enfermeiro supervisor na formação do profissional, observou-se que os estudantes têm expectativas sobre este, resumidas em auxiliarem no desempenho do trabalho emocional, na visão holística sobre o ser humano, na interação afetiva, com função de suporte nas ações e respostas do estudante (Diogo et al., 2016).

Quando tais atitudes provenientes do enfermeiro supervisor ocorrem, os discentes conseguem desenvolver competências fulcrais na capacidade de gerir emocionalmente as situaçóes presentes no exercício da enfermagem (Diogo et al., 2016).

Muito embora a atuação direta sobre o ensino-aprendizagem discente ocorra junto dos enfermeiros supervisores, mediada pelos enfermeiros docentes, são necessárias ações voltadas para os componentes que, mesmo indiretamente, tem influência sobre o espaço de ensino na APS. Neste cenário, são coadjuvantes a IES e a instituição de saúde. Os seus papéis, na esfera política de organização e manutenção do estágio supervisionado, sugerem açóes de arranjos dos detalhes, não menos importantes, mas que sem a devida atenção impactam profundamente o processo de ensino.

Num município próximo ao local de execução deste estudo, práticas de articulação de negociação, ocorridas antes do nível operacional do ensino na APS, têm sido realizadas mensalmente e apresentam-se positivas, no sentido de avaliarem os semestres anteriores para melhor planeamento do semestre seguinte. Percebeu-se que reuniōes realizadas previamente, quando incluem a gestáo institucional, levaram ao empoderamento da gestão, sendo assim, tais setores já discutem a escolha dos centros de saúde, dos orientadores e avaliam problemas e conflitos nas relaçóes. Isso leva a construção de cronogramas compartilhados com os centros de saúde, sobre quais atividades irão ocorrer em conformidade com cada disciplina (Andrade et al., 2014). Nesse sentido, o envolvimento de todos os atores que compóem essa esfera de ensino é importante para o desenvolvimento do sentimento de pertencer à organização do ensino no serviço da APS.

Atualmente, devido à inexistência de uma diretriz comum que oriente tais organizaçóes prévias, é esperado que se revelem inconformidades no conjunto de espaços de efetivação deste ensino, firmando uma operacionalizaçáo individual de cada instituiçáo.

Diante desta problemática e da proposição de ações que 
fomentem melhores arranjos, pretende-se que este estudo avance na indução de políticas e diretrizes que norteiem melhores práticas a nível de gestão, da inclusão do ensino no serviço da APS, com maior envolvimento intersetorial. Como limitaçóes do estudo, destaca-se a necessidade de incluir a perceção dos estudantes, acerca das açóes necessárias ao ensino na APS.

\section{Conclusão}

Com o desenvolvimento da comunidade de prática e das suas dimensóes de engajamento mútuo, repertório compartilhado e objetivo comum, percebeu-se a sugestão de açóes por parte dos docentes de enfermagem: a necessidade de estabelecimento de papéis sobre a sua atuação na docência enquanto no espaço de ensino; preparação e troca antecipada de ideias entre enfermeiro docente e enfermeiro supervisor, no que diz respeito aos conteúdos e assuntos necessários ao ensino na APS, conforme as particularidades das unidades de saúde. Estes referiram que o trabalho da equipa também é um fator que reflete ao ensino do estudante de enfermagem; estabelecendo a tomada de decisão sobre a escolha das atividades educativas, tendo em conta o currículo do curso e a fase em que o discente está em determinado momento.

Os enfermeiros supervisores corroboram a questão da atuação da equipa na formação do profissional enfermeiro, reforçando a necessidade de serem exemplos para os discentes em enfermagem; além de reconhecerem a importância que possuem no estímulo aos discentes para participarem nas atividades junto deles, envolvendo também os professores, docentes das IES.

Relativamente às açóes coletivas, ambos os intervenientes expressam a necessidade de antecipar o contacto da IES com a UBS antes de desenvolverem o processo de ensino, referindo que a sensibilização acerca das políticas de saúde e da importância desse espaço para a formação do SUS, deva ser sensibilizada junto da equipa e também, com a gestão da instituiçáo de saúde. Tais colocaçóes demonstraram uma certa compreensão de que a inserção do grupo vai além do processo de ensino-aprendizagem do aluno, pois contribuiria para o trabalho das unidades de saúde. Os resultados deste estudo podem ser um indicativo para as políticas públicas de formação permanente de professores e enfermeiros supervisores, quanto à potencialidade de espaços semelhantes aos grupos desta comunidade de prática, dado o formato que a mesma apresenta para ser considerada de facto uma comunidade de prática. A partir do estudo, percebe-se a comunidade de prática como uma alternativa para o desenvolvimento profissional e para a antecipação de açóes que efetivem qualitativamente o ensino na APS.

\section{Contribuição de autores}

Conceptualização: Zamprogna, K. M., Backes, V. M. Tratamento de dados: Zamprogna, K. M., Backes, V. M. Análise formal: Zamprogna, K. M., Backes, V. M., Menegaz, J. C., Silva, G. T., Oliveira, M. L., Fraga, F. M., Tristão, F. R.
Investigação: Zamprogna, K. M., Backes, V. M., Menegaz, J. C.

Metodologia: Zamprogna, K. M., Backes, V. M., Menegaz, J. C.

Administração do projeto: Zamprogna, K. M., Backes, V. M.

Recursos: Zamprogna, K. M., Backes, V. M.

Software: Zamprogna, K. M., Backes, V. M.

Validação: Silva, G. T., Oliveira, M. L.

Visualização: Silva, G. T., Oliveira, M. L., Fraga, F. M., Tristão, F. R.

Redação - rascunho original: Zamprogna, K. M., Backes, V. M., Menegaz, J. C., Silva, G. T., Oliveira, M. L., Fraga, F. M., Tristão, F. R.

Redação - análise e edição: Menegaz, J. C., Silva, G. T., Oliveira, M. L., Fraga, F. M., Tristão, F. R.

\section{Referências bibliográficas}

Andrade, S. R., Boehs, A. E., Coelho, B., Scmitt, I. M., \& Boehs, C. G. (2014). Relacionamento inter organizacional na integraçáo ensino-serviço de enfermagem na atenção primária à saúde. Revista Brasileira de Enfermagem 67(4), 520-527.https://doi. org/10.1590/0034-7167.2014670404

Backes, V. M., Menegaz, J. C., Miranda, F. A., Santos, L. M., Cunha, A. P., \& Patrício, S. S. (2017). Lee Shulman: Contribuiçôes para a investigação da formação docente em enfermagem e saúde. Texto \& Contexto Enfermagem, 26(4), 1-9. https://doi.org/10.1590/010407072017001080017

Bardin, L. (2011). Análise de conteúdo (70ª ed). Lisboa, Portugal: Persona.

Brehmer, L. C., \& Ramos, F. R. (2017). Experiências do programa de reorientação da formação profissional na enfermagem: Avanços e desafios. Texto \& Contexto Enfermagem, 26(2), 1-8. https://doi. org/10.1590/0104-07072017003100015

Diogo, P., Rodrigues, J., Sousa, O. L., Martins, H., \& Fernandes, N. (2016). Supervisão de estudantes em ensino clínico: Correlação entre desenvolvimento de competências emocionais e função de suporte. Revista Portuguesa de Enfermagem de Saúde Mental, ( $\mathrm{n}^{\circ}$ esp.4), 115-122. http://dx.doi.org/10.19131/rpesm.0150

Herold, F. (2019). Shulman, or Shulman and Shulman? How communities and contexts affect the development of pre-service teachers' subject knowledge. Teacher Development, 23(4), 488-505. https:// doi.org/10.1080/13664530.2019.1637773

Hita, N. H., Mancebo, C. A., Jiménez, L. V., \& Otero, D. P. (2018). El foro de discusión como herramienta docente em prácticas tuteladas del grado em enfermería. Revista de Enfermagem Referência, 4(17), 131-142. https://doi.org/10.12707/RIV17101

Ministério da Saúde, Secretaria de Gestão do Trabalho e da Educação na Saúde, Departamento de Gestão da Educação na Saúde. (2004). Aprender SUS: O SUS e os cursos de graduação da área da saúde. Brasília, Brasil: Autor. https://bvsms.saude.gov.br/bvs/publicacoes/ cartilha_aprender_sus.pdf

Ministério da Saúde. (2004). Portaria ministerial no 198, de 13 de fevereiro de 2004. Brasília, Brasil: Autor. https://www.nescon. medicina.ufmg.br/biblioteca/imagem/1832.pdf

Ministério da Saúde. (2017). Portaria ministerial no 2.436, de 21 de setembro de 2017. Brasília, Brasil: Autor. https://bvsms.saude.gov. br/bvs/saudelegis/gm/2017/prt2436_22_09_2017.html 
Moya, J. L., Borrasc, B. J., \& Menegaz, J. C. (2018). A formalização do conhecimento profissional no currículo. Revista Ibero-Americana de Estudos em Educação, 13(2), 588-603. https://periodicos.fclar. unesp.br/iberoamericana/article/view/11323/7356 https://doi. org/10.21723/riaee.v13.n2.2018.11323

Pinto, T. R., \& Cyrino, E. G. (2015). Com a palavra, o trabalhador da atenção primária à saúde: Potencialidades e desafios nas práticas educacionais. Interface, 19(sup. 1), 765-777. https://doi. org/10.1590/1807-57622014.0991

Rostelatto, M. T., \& Dallacosta, F. M. (2018). Vivências do acadêmico de enfermagem durante o estágio com supervisão direta. Enfermagem em Foco, 9(4), 34-38. https://pdfs.semanticscholar.org/ ba12/7aeb807b7c7ff8c2a37ea233104ca26460ce.pdf

Sales, P. R., Marin, M. J., \& Filho, C. R. (2015). Integração academia-serviço na formaçáo de enfermeiros em um hospital de ensino. Trabalho Educação e Saúde, 13(3), 675-693. https://doi. org/10.1590/1981-7746-sip00057

Shing, L. C., Saat, R. M., \& Loke, S. H. (2015). The knowledge of teaching- pedagogical content knowledge. The Malasyan Online Journal of Educational Science, 3(3), 40-55. https://mojes.um.edu. my/article/view/12781/8206

Shulman, L. S. (2005). Conocimiento y enseñanza: Fundamentos de la nueva reforma. Profesorado: Revista de Curriculum y Formación del Professorado, 9(2), 1-30. https://recyt.fecyt.es/index.php/profesorado/article/view/42675

Silva, F. A., Costa, N. M., Lampert, J. B., \& Alves, R. (2018). Papel docente no fortalecimento das políticas de integração ensino-serviço-comunidade: Contexto das escolas médicas brasileiras. Interface 22(1), 1411-1423. https://doi.org/10.1590/180757622017.0062

Wenger, E. (2011). Comunidades de práctica: Aprendizaje, significado e identidade ( $2^{\mathrm{a}}$ ed.). Barcelona, Espańa: Paidós Ibérica.

Zarpelon, L. F., Terencio, M. L., \& Batista, N. A. (2018). Integração ensino-serviço no contexto as escolas médicas brasileiras: Revisão integrativa. Ciência e Saúde Coletiva, 23(12), 4241-4248. https:// doi.org/10.1590/1413-812320182312.32132016 